\title{
Strategic Allocation of Attention Reduces Temporally Predictable Stimulus Conflict
}

\author{
L. Gregory Appelbaum ${ }^{1}$, Carsten N. Boehler ${ }^{1,2}$, Robert Won ${ }^{1}$, \\ Lauren Davis ${ }^{1}$, and Marty G. Woldorff ${ }^{1}$
}

\begin{abstract}
Humans are able to continuously monitor environmental situations and adjust their behavioral strategies to optimize performance. Here we investigate the behavioral and brain adjustments that occur when conflicting stimulus elements are, or are not, temporally predictable. ERPs were collected while manual response variants of the Stroop task were performed in which the SOAs between the relevant color and irrelevant word stimulus components were either randomly intermixed or held constant within each experimental run. Results indicated that the size of both the neural and behavioral effects of stimulus incongruency varied with the temporal arrangement of the stimulus components, such that the random-SOA arrangements pro-
\end{abstract}

\section{INTRODUCTION}

Activities in everyday life require us to attend selectively to certain features in the environment while excluding other irrelevant or distracting information that may lead us to the wrong or less appropriate action. A fundamental and widely studied aspect of human psychology deals with the allocation of attentional resources and cognitive control faculties to resolve distracting or conflicting environmental stimuli. Experimental paradigms that pit competition between target stimuli and irrelevant distractors, such as the Stroop (Stroop, 1935), Simon (Simon, 1990), and Flanker (Eriksen \& Eriksen, 1974) tasks, have proved extremely fruitful in elucidating the behavioral (MacLeod, 1991; Miller, 1991) and brain (Egner, 2008; Roberts \& Hall, 2008; MacLeod \& MacDonald, 2000) mechanisms that are invoked in response to situations that elicit conflicting response tendencies. While numerous studies have successfully invoked some form of conflict effect, the presence and degree of interference evoked by competing stimuli have been shown to depend heavily on the arrangement of incompatible elements in the environment (Reynolds, Kwan, \& Smilek, 2010), the strategies used by observers to focus on and select relevant information (Egner, 2007; Scerif, Worden, Davidson, Seiger, \& Casey, 2006; Tzelgov, Henik, \& Berger, 1992), and the manner in which stimuli need to

${ }^{1}$ Duke University, ${ }^{2}$ Ghent University duced the greatest incongruency effects at the earliest irrelevant first SOA (-200 msec) and the constant-SOA arrangements produced the greatest effects with simultaneous presentation. These differences in conflict processing were accompanied by rapid ( $\sim 150 \mathrm{msec}$ ) modulations of the sensory ERPs to the irrelevant distractor components when they occurred consistently first. These effects suggest that individuals are able to strategically allocate attention in time to mitigate the influence of a temporally predictable distractor. As these adjustments are instantiated by the participants without instruction, they reveal a form of rapid strategic learning for dealing with temporally predictable stimulus incongruency.

be translated into specific responses (e.g., Coderre, van Heuven, \& Conklin, 2010; Sugg \& McDonald, 1994).

The strategic allocation of attention is a key aspect of behavioral control that allows individuals to optimize performance in the face of conflicting stimulus input by generating, maintaining, and adjusting sets of goal-directed processing tactics. The determination and reinforcement of such task sets reflect the operation of multiple, complementary processes that are determined by top-down objectives and ongoing regulatory control processes as they interact with the dynamically changing array of stimulus input. Critical aspects of the allocation of attentional resources for the purpose of resolving conflict have been demonstrated to operate both over space and over time. Whereas spatial attention has been the subject of substantial research efforts, the orienting of attention in time (e.g., Nobre, 2001) has received considerably less focus. One notable exception to this has been in a family of experiments that have manipulated the SOA between component parts of the stimuli used in the color-naming Stroop task to study the time course of the incongruency effects in this well-known paradigm (Roelofs, 2003, 2005, 2006, 2010; Appelbaum, Meyerhoff, \& Woldorff, 2009; Lu \& Proctor, 2001; Starreveld \& La Heij, 1996; Sugg \& McDonald, 1994; Glaser \& Glaser, 1982, 1989; Long \& Lyman, 1987; Rayner \& Springer, 1986; Glaser \& Dungelhoff, 1984; Dyer, 1971; see also Mattler, 2003; Flowers, 1990, for related Flanker-SOA tasks). 
In these Stroop-SOA experiments, the onset of a taskirrelevant distractor feature (the word in the Stroop task) is separated in time from the onset of the task-relevant target element (the color patch), with temporal separations typically ranging from -400 to +400 msec. In general, Stroop behavioral effects in these tasks, such as the relative slowing of RTs for incongruent versus congruent stimuli, has been found to be maximal when the color patch and word were presented close to each other in time (i.e., with a zero SOA), with the size of this incongruency effect falling off monotonically in both directions as the irrelevant stimulus was presented earlier or later than the target stimulus (i.e., an inverted u-shape function). Although these studies have provided a useful depiction of the behavioral time course of facilitation and interference effects and have served as the basis of important computational models of human cognition (Stafford \& Gurney, 2007; Roelofs, 2003; Zhang, Zhang, \& Kornblum, 1999; Cohen, Dunbar, \& McClelland, 1990; Phaf, Van der Heijden, \& Hudson, 1990), they have typically only used trial arrangements where the SOA between the target and distractor elements was held constant in a given experimental run. Accordingly, the typical inverted u-shaped interference function obtained in these "constant-SOA" tasks could be partly explained by assuming that participants were able to deduce the predictable temporal structure of trials within a block. This simple inference would then allow participants to implement an attentional filter that selectively modulates the visual input over time, opening and closing dynamically to attenuate the influence of irrelevant distractors not temporally aligned with the target (Yu \& Choe, 2006; Broadbent, 1970).

In previous work by our group (Appelbaum, Meyerhoff, et al., 2009), behavioral and ERP measures in variants of the Stroop-SOA tasks showed a distinctly different pattern of effects. In these studies, the SOAs were randomly intermixed from trial to trial within an experimental run, which led to maximal incongruency effects being observed at the earliest tested pre-exposure SOAs (i.e., when the word information was presented before the color), with the magnitude of these effects decreasing monotonically with later SOAs. These differences suggest that participants may be exploiting different strategies to more effectively filter irrelevant information based on the composition of SOA trials within an experimental run (see Roelofs, 2010, and discussion of below, for a contrary view). Moreover, in that conflicting stimulus elements in the world very frequently do not occur in a temporally predictable fashion, a fundamental open question is to what degree conflict resolution mechanisms can flexibly adjust to differing environmental demands with differing levels of temporal predictability.

In this study, we directly tested for such possible strategic adjustments by having the same set of participants perform separate Stroop-SOA tasks in which temporal separations between the color and word elements were either random or constant within an experimental run. We focused on task and SOA effects on two wellestablished Stroop-related ERP components: the negative- polarity ERP wave associated with incongruency ${ }^{1}\left(\mathrm{~N}_{\mathrm{INC}}\right)$, thought to reflect conflict-induced interference processes in the brain (Larson, Kaufman, \& Perlstein, 2009; Hanslmayr et al., 2008; Perlstein, Larson, Dotson, \& Kelly, 2006; West, Jakubek, Wymbs, Perry, \& Moore, 2005; West, 2003; Van Veen \& Carter, 2002; Liotti, Woldorff, Perez, \& Mayberg, 2000; West \& Alain, 1999), and the late positivity component $^{2}$ (LPC), proposed to reflect semantic re-evaluation or postconflict processes (Hanslmayr et al., 2008; Liotti et al., 2000). For this purpose, we pursued to specifically assess the amplitudes and latencies of these components to determine what, if any, stage of the cortical processing showed dependence on the temporal predictability of stimulus conflict.

In addition to expected effects of SOA arrangement on the conflict-related $\mathrm{N}_{\mathrm{INC}}$ and LPC components, we also anticipated that the temporal predictability of stimulus elements would lead to context-specific modulation of the sensory processing of the stimulus input. Accordingly, we planned to analyze the sensory-evoked potentials to the task-irrelevant stimulus component when it preceded the target to assess if such arrangements revealed differential processing of the irrelevant distractor input when it came predictably first versus when the temporal arrangement was random. Such modulations of early visual ERP responses to these task-irrelevant stimulus inputs would provide direct evidence for early sensory modulation being a key part of the neural adjustments that accompany the strategic allocation of attention in time for reducing the effects of temporally predictable conflicting stimulus input.

\section{METHODS \\ Participants}

Thirteen neurologically intact participants with normal or corrected-to-normal visual acuity participated in the present experiments. All participants were screened for colorblindness, and informed consent was obtained before experimentation under a protocol approved by the Duke University Institutional Review Board. Participants were instructed on the task and given practice experimental runs before the start of each experimental session. All participants were paid $\$ 15 / \mathrm{hr}$ for their participation and participated in two session on different days spaced no more than 2 weeks apart. The data from three participants were excluded from the final behavioral and ERP analyses because of problematically high levels of EEG artifact (e.g., eye blinks) or failure to complete both sessions, leaving 10 participants in the final analyses (mean age $=25$ years, five women, eight right-handed).

\section{Experimental Design and Procedure}

Examples of experimental stimuli and task parameters are illustrated in Figure 1. Stimuli consisted of red-, green-, blue-, or yellow-colored horizontal rectangular patches 
Figure 1. Schematic illustration of stimuli and tasks. (A) Examples of congruent and incongruent stimuli with stimulus dimensions. (B) Schematic illustration of the timing sequence for the two stimulus components at each SOA condition. Each temporal separation $(-200,-100,0$, +100 , and $+200 \mathrm{msec}$ ) is shown in a separate row with vertical, dotted lines indicating times at which stimuli components were presented. Once both stimulus components were presented, they remained on the screen for an additional $1000 \mathrm{msec}$ until the fixation screen reappeared. The participant's task was always to report the color of the bar, which was defined as $0 \mathrm{msec}$ in this schematic. (C) Schematic of SOA trial-type arrangements over successive $\sim 3$ min runs for the constant-SOA and random-SOA tasks.

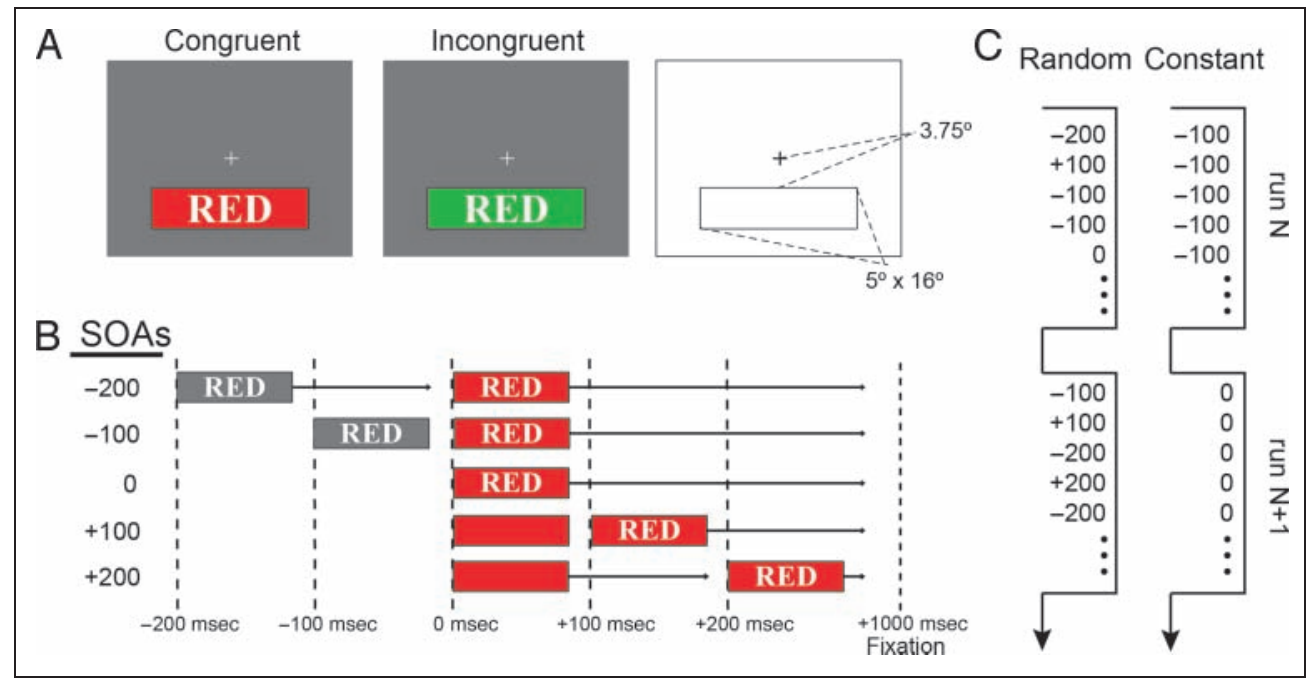

overlaid with English color-word text strings "RED," "GREEN," "BLUE," or "YELLOW," written in white font with black borders and positioned in the center of the rectangular patch. These stimuli were presented on a gray screen with a white fixation cross at the center. Colored bars subtended $5^{\circ} \times 16^{\circ}$ and were centered $3.75^{\circ}$ below fixation.

The current experimental design consisted of three independent variables that were varied for each subject. The first independent variable was "Stroop congruency," which was defined by the correspondence between the color bar physical color and the written word meaning on each trial (Figure 1A). In all experimental sessions, congruent pairings appeared on half of the trials (redRED, green-GREEN, blue-BLUE, yellow-YELLOW), whereas the other half of the trials were split evenly between the 12 possible noncorresponding, incongruent pairings (red-GREEN, red-BLUE, red-YELLOW, greenRED, green-BLUE, green-YELLOW, blue-RED, blueGREEN, blue-YELLOW, yellow-RED, yellow-GREEN, yellow-BLUE).

The second independent variable was the SOA between the presentation of the task-irrelevant distractor word and the target color bar (Figure 1B). There were five levels of SOA $(-200,-100,0,+100$, and $+200 \mathrm{msec})$ so that the task-irrelevant word stimulus could precede the target color bar ( -200 and -100 msec conditions), occur simultaneously with it ( 0 msec or "no delay"), or follow it $(+100$ and +200 msec).

The third independent variable was "SOA arrangement" (Figure 1C). In separate experimental sessions administered on separate days, participants were either presented with a "random-SOA" arrangement in which all five SOA conditions were intermixed and appeared randomly within each experimental run, or they were presented with a "constant-SOA" arrangement, in which the same SOA was presented on every trial in an experimental run. Constantand random-SOA session orders were counterbalanced over participants. For half of the participants, the constantSOA runs progressed $-200,-100,0,100,+200$, with the same SOA type being maintained throughout three successive runs. In the other half of the participants, this order was reversed. As no difference was observed in the RT or error rates based on the order of constant-SOA runs, the data was collapsed over this factor for all subsequent analyses (see Supplementary Figure 1).

In all cases, the participants' task was to report the physical color of the color bar stimulus as quickly as possible, while ignoring the semantic meaning of the task-irrelevant word. In the random-SOA and constant-SOA task variants, participants were instructed to respond manually by pressing one of four keys on the keyboard corresponding to four possible colors, indicated with colored stickers attached to the letter keys (see Sugg \& McDonald, 1994, for a discussion of feature translation issues related to the mapping of stimulus-response associations). Red and green responses were mapped to the "D" and "F" keys of the left hand, and blue and yellow were mapped to the "J" and "K" keys on the right hand.

For all tasks, participants were instructed to maintain central fixation and to minimize eye blinks during the experimental run. RTs and error rates were monitored while 64-channel EEG was recorded. On every trial, the color bar and the color word remained on the screen together 
for 1000 msec after the onset of the later of the two stimulus components. Individual trials were separated by a trial onset asynchrony that varied randomly between 1300 and 1700 msec, with only the fixation cross remaining on the screen in between trials. Each run consisted of 48 trials and lasted approximately $3 \mathrm{~min}$. Before recording began, participants were given one or two training runs to learn the mapping of the four-color response buttons. A total of 15 runs were collected for each participant in each of two experimental sessions, and participants were given the opportunity to rest between the runs. Each of the two tasks (random-SOA and constant-SOA) had the same number of trials, and the order was counterbalanced such that half of the participants performed one of the tasks during the first session, and the other half performed the other task first.

\section{Data Acquisition and Analysis}

\section{Behavioral Analysis}

Behavioral responses were monitored and recorded while participants performed the color-naming task. Trials were counted as correct if the participant responded correctly between 200 and 1000 msec following the presentation of the target color bar. As no systematic behavioral differences were observed for the four different colors of the target color bars, data were collapsed over the different colors to arrive at within-participant mean RTs (correct trials only) and error rates for the congruent and incongruent instances of the five SOA conditions. RT and error rates were submitted to repeated-measures ANOVAs (rANOVAs), with factors Congruency (two levels), SOA (five levels), and SOA Arrangement (two levels). Additional two-tailed, paired $t$ tests were performed on the incongruent minus congruent RT and error rate differences between the two tasks (constant and random) for each SOA. The significance thresholds were set to a $p$ value of .05 and, when applicable, adjusted using the Greenhouse-Geisser correction for nonsphericity. Partial eta-square values $\left(\eta_{p}{ }^{2}\right)$ are reported as a metric of effect size for each ANOVA contrast.

\section{ERP Recording and Analysis}

The EEG was recorded continuously from 64 channels mounted in a customized elastic cap (Electro-Cap International, https://www.electro-cap.com) using a bandpass filter of 0.01-100 Hz at a sampling rate of $500 \mathrm{~Hz}$ (SynAmps, Neuroscan, El Paso, TX). All channels were referenced to the right mastoid during recording. The positions of all 64 channels were equally spaced across the customized cap and covered the whole head from slightly above the eyebrows to below the inion (Woldorff et al., 2002). Impedances of all channels were kept below $5 \mathrm{k} \Omega$, and visual fixation was monitored with both EOG recordings and a zoom-lens camera. Recordings took place in an electri- cally shielded, sound-attenuated, dimly lit, experimental chamber.

For each participant, ERPs to the onset of the colored bars were selectively averaged for each condition and SOA. ERP processing included the re-referencing of all channels to the algebraic mean of the two mastoid electrodes. A digital, noncausal, 9-point running average filter was applied to the ERP averages, which greatly reduces signal at frequencies of $56 \mathrm{~Hz}$ and above at our sampling frequency of $500 \mathrm{~Hz}$. Artifact rejection was performed off-line before averaging by excluding epochs of the EEG that exceeded a specifiable threshold in the window from -200 to 900 msec around a given event type. The artifact rejection thresholds were set individually for each subject. An average of $13 \%$ of the trials was rejected, per subject, leaving an average of 628 total trials per condition in the grand average.

Separate ERPs were computed for correctly reported congruent and correctly reported incongruent presentations at each of the five SOA conditions ( $-200,-100,0$, $+100,+200)$ by time-locking to the onset of the target color bar stimulus. As with the behavioral performance, because no differences were observed in the ERP responses for the different colors of the target color bars, responses were collapsed over the different colors, yielding 10 (5 SOA $\times 2$ congruency conditions) evoked response types for each experimental task. To isolate brain potentials related to the Stroop incongruency effect under the different conditions, difference waves were computed by subtracting the ERPs for congruent trials from the ERPs for incongruent trials, separately for each SOA in each SOA arrangement condition. We explicitly focus our ERP analyses here on the incongruency difference waves, because the SOA manipulation utilized in these experiments introduces differential amounts of overlap in the ERP record depending on the temporal separation between stimulus components (Woldorff, 1993). As this overlap is equivalent for the congruent and incongruent stimuli within each SOA condition, the difference wave isolates processes related to the Stroop stimulus incongruency and serves as a principled ERP marker for assessing interactions between the SOA and the neural processing related to the conflict processing interactions.

Statistical analyses of the SOA-incongruency effects were carried out using four ROIs to separately test for effects of stimulus congruency and sensory biasing. First, to test for effects of congruency, a six-channel ROI was derived from our previous Stroop experiments that also roughly corresponded to the peaks of the incongruency effects for the current random-SOA and constant-SOA tasks (see orange dots in Figure 3). This ROI consisted of same set of posterior-parietal left (P01, P1) and right (P02, P2) channels as was used in our previous article (Appelbaum, Meyerhoff, et al., 2009). However, because lateralization was not considered as a factor here, as it was in our previous article, the midline channels $\mathrm{CPz}$ and $\mathrm{Pz}$ were also included in the ROI for this study. 
To test for main effects and interactions of SOA and SOA arrangement, peak amplitude values of the negative ( $\mathrm{N}_{\mathrm{INC}}$ ) and positive (LPC) incongruency difference waves (incongruent minus congruent) were submitted to rANOVA. Local peak amplitudes were extracted by first identifying the peak latency of the $\mathrm{N}_{\mathrm{INC}}$ and LPC components for each SOA. Next, the peak voltage falling within $\pm 150 \mathrm{msec}$ of this time point was extracted for each participant and at each channel. These values were then averaged and subjected to rANOVA with factors SOA and SOA Arrangement. In addition, the peak latency values were submitted to rANOVAs to infer the presence of significant linear trends in the data. Task interactions were statistically explored further through paired $t$ tests.

To test for evidence for differential sensory processing of the stimuli between the random- and constant-SOA task blocks, we probed for task differences in the -200 msec SOA condition. This condition provides an uninterrupted window for 200 msec from the onset of Stimulus component 1 (S1) until the onset of Stimulus component 2 (S2), during which no other overlapping stimulus response activity would be present. On the basis of previous reports of cortical biasing due to attentional selection (Hillyard \& Anllo-Vento, 1998; Anllo-Vento \& Hillyard, 1996), we probed the response amplitudes over ROIs comprised of frontal-central sensors Cz, FCz, C1a, and C2a, left posterior sensors (O1i, O1', TO1, P3i), and right posterior sensors (O2i, O2', TO2, P4i). These ROIs also corresponded roughly to the peaks of the random- minus constant-SOA subtraction for the $-200 \mathrm{msec}$ SOA condition and are depicted by the orange dots in Figure 5. Mean amplitude values computed over $25 \mathrm{msec}$ windows extending from 0 to 250 msec following the S1 stimulus were derived for each four-channel ROI and were submitted to rANOVA where they were compared with the $100 \mathrm{msec}$ baseline preceding the presentation of the S1 stimulus.

\section{RESULTS}

\section{Behavioral Performance}

Robust and statistically significant behavioral effects of stimulus incompatibility were observed in both the randomSOA and constant-SOA variants of these tasks. For both tasks, RTs were faster for congruent trials than for incongruent trials. Similarly, error rates were generally lower for congruent trials than incongruent trials. Mean RTs for the two tasks are shown graphically in Figure 2 and are presented along with paired $t$ test results in Table 1 .

For general statistical evaluation of these data, $2 \times 5 \times 2$ (Congruency $\times$ SOA $\times$ SOA Arrangement), rANOVAs were performed separately on the RT and percentage error data. The rANOVA for the RTs demonstrated a significant main effect of both Congruency $\left[F(1,9)=128.70, p<.001, \eta_{p}{ }^{2}=\right.$ $0.93]$ and SOA $\left[F(4,36)=25.98, p<.001, \eta_{p}{ }^{2}=0.74\right]$ and a significant Congruency $\times$ SOA Interaction $[F(4,36)=$ $\left.11.1, p<.001, \eta_{p}{ }^{2}=0.55\right]$. Critically, there was also a significant Congruency $\times$ SOA $\times$ SOA Arrangement interaction $\left[F(4,36)=3.69, p=.03, \eta_{p}{ }^{2}=0.29\right]$, indicating that the effect of SOA on Stroop incongruency differed, depending on the arrangement of SOA conditions within a run. More specifically, this effect appeared to be because of the incongruency effect being largest at the 0 SOA for the constant-SOA arrangement, whereas it was largest at the -200 SOA in the random-SOA case. For the error rates (shown graphically in Supplementary Figure 2), the threeway ANOVA showed only a significant main effect of Congruency $\left[F(1,9)=17.01, p=.003, \eta_{p}{ }^{2}=0.65\right]$ and $a$

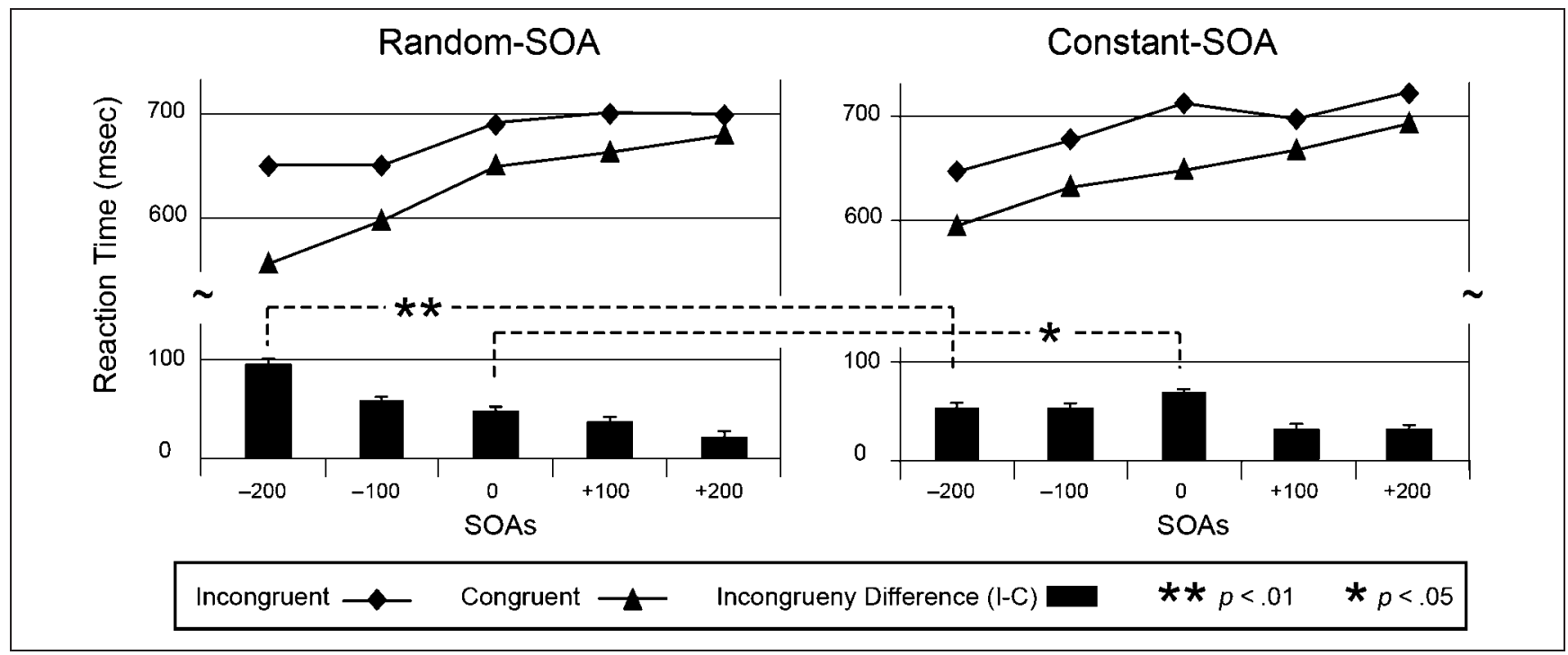

Figure 2. SOA arrangement alters the pattern of incongruency effects. RTs for the random-SOA and constant-SOA variants of the Stroop task produced different profiles of SOA-incongruency interactions. Although statistically significant behavioral incongruency effects were observed across all SOA conditions (see Table 1), incongruency effects were maximal at the earliest distractor-exposure condition for the random-SOA arrangement $(-200 \mathrm{msec})$ but was largest at the simultaneous $(0 \mathrm{msec})$ condition for the constant-SOA arrangement. Error bars indicate 1 SEM. 
Table 1. Summary of Incongruency Differences for the Two SOA Arrangements

\begin{tabular}{|c|c|c|c|c|c|c|}
\hline$S O A$ & RT Difference (msec) & $t$ & $p$ (Two Tail) & Error Rate Difference (\%) & $t$ & $p$ (Two Tail) \\
\hline \multicolumn{7}{|c|}{ (a) Random-SOA (Incongruent vs. Congruent) } \\
\hline-200 & 94.57 & $t(9)=9.07$ & $.001 * *$ & 2.96 & $t(9)=2.23$ & .053 \\
\hline-100 & 58.86 & $t(9)=5.78$ & $.001 * *$ & 1.91 & $t(9)=2.19$ & .056 \\
\hline 0 & 47.94 & $t(9)=5.81$ & $.001 * *$ & 2.58 & $t(9)=3.52$ & $.006 * *$ \\
\hline 100 & 37.73 & $t(9)=4.41$ & $.002 * *$ & 0.50 & $t(9)=0.44$ & .667 \\
\hline 200 & 23.28 & $t(9)=2.53$ & $.032 *$ & -0.85 & $t(9)=-1.01$ & .338 \\
\hline \multicolumn{7}{|c|}{ (b) Constant-SOA (Incongruent vs. Congruent) } \\
\hline-200 & 51.60 & $t(9)=7.91$ & $.001 * *$ & 1.77 & $t(9)=1.37$ & .205 \\
\hline-100 & 48.84 & $t(9)=5.80$ & $.001 * *$ & 2.31 & $t(9)=2.71$ & $.024 *$ \\
\hline 0 & 67.24 & $t(9)=7.69$ & $.001 * *$ & 2.64 & $t(9)=2.69$ & $.025 *$ \\
\hline 100 & 30.76 & $t(9)=4.25$ & $.002 * *$ & 1.48 & $t(9)=1.50$ & .169 \\
\hline 200 & 30.19 & $t(9)=2.94$ & $.017^{*}$ & 1.39 & $t(9)=1.94$ & .085 \\
\hline \multicolumn{7}{|c|}{ (c) Task Differences (Random-SOA Minus Constant-SOA) } \\
\hline-200 & 42.96 & $t(9)=3.36$ & $.008 * *$ & 1.18 & $t(9)=0.61$ & .554 \\
\hline-100 & 10.01 & $t(9)=0.83$ & .427 & -0.41 & $t(9)=-0.34$ & .744 \\
\hline 0 & -19.31 & $t(9)=-2.89$ & $.018^{*}$ & -0.06 & $t(9)=-0.45$ & .965 \\
\hline 100 & 6.97 & $t(9)=0.68$ & .521 & -0.97 & $t(9)=-0.56$ & .589 \\
\hline 200 & -6.91 & $t(9)=-0.45$ & .661 & -2.24 & $t(9)=-1.93$ & .086 \\
\hline
\end{tabular}

Group mean RT and error rate differences and paired $t$ test results for all within-SOA contrasts of incongruent minus congruent trials.

$* p<.05$.

$* * p<.01$.

significant Congruency $\times$ SOA interaction $[F(4,36)=3.18$, $\left.p=.047, \eta_{p}^{2}=0.26\right]$.

To further explore interactions between experimental variables, paired $t$ tests were performed between the incongruent and congruent RTs and error rates at each SOA (Table $1 \mathrm{a}$ and $\mathrm{b}$ ) and for the incongruent minus congruent differences for the two SOA arrangements (Table 1c). These planned comparisons revealed that behavioral incongruency effects were present at all SOAs and for both tasks, as depicted by the black bars in Figure 2 showing the incongruency differences for each SOA; however, the greatest behavioral incongruency effects occurred at different SOAs for the two tasks. Between-task, paired $t$ tests reveal that this pattern is driven by a significant reduction in the amount of incongruency effect for the constant-SOA arrangement at the -200 SOA (42.96 msec; $t=3.36, p=.008$ ), whereas the behavioral incongruency effect was significantly larger at the $0 \mathrm{msec}$ SOA for the constant-SOA arrangement $(-19.31 \mathrm{msec} ; t=-2.89$, $p=.018)$. Additional, direct comparisons between the congruent and incongruent trial types indicate that the effect at the -200 msec SOA is largely driven by a reduction in
RTs for the congruent trial types $(p=.038)$, whereas the difference for incongruent trials was not significant $(p=.19)$. The task differences were not significant at the 0 msec SOA for either trial type alone (congruent, $p=.3$; incongruent, $p=.23$ ). No significant congruency differences were observed between the RT or error rates at any other SOAs.

\section{Electrophysiological Incongruency Effects as a Function of SOA Arrangement}

Having established at the behavioral level both that Stroop incongruency was robustly evoked over a range of SOA separations and that the pattern of SOA-incongruency interaction depended on the contextual arrangement of SOA trials over the course of an experimental run, we examined how these effects are manifested in the brain. For this purpose, we compared the peak amplitude profiles of the negative and positive incongruency difference waves over central-parietal cortex using ROIs derived from our previous experiments (Appelbaum, Meyerhoff, et al., 2009). As before, this ROI roughly corresponded to the peak of the incongruency difference distributions for both 
Figure 3. ERP incongruency difference waves for the random-SOA and constant-SOA variants of the Stroop task. Group-averaged difference waves (incongruent minus congruent) computed over the six-channel ROI (depicted in the lower right) are shown for the five SOAs in each task. The pattern of ERP incongruency effects, as a function of the SOA, differed between the random- and constant-SOA conditions, indicating that Stroop incongruency depended on the contextual arrangement of SOA trials over the course of an experimental run.

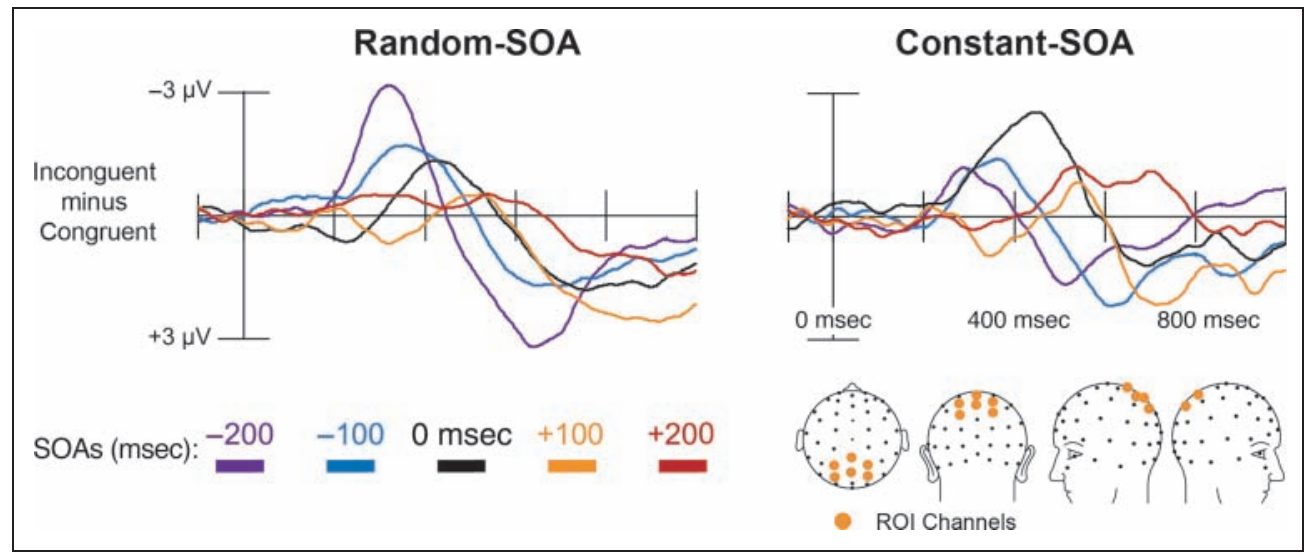

the random-SOA and constant-SOA tasks (see Supplementary Figure 3 for full spatio-temporal profiles of the effects).

Figure 3 shows the ROI incongruency difference wave for each of the five SOAs in the two versions of the task. Two primary observations are easily visible in these waveforms. First, for both task variants, the grand-averaged difference waves contained both earlier-latency negativepolarity effects $\left(\mathrm{N}_{\mathrm{INC}}\right)$ and the longer-latency positivepolarity effects (LPC) that followed roughly monotonic patterns in which the later SOAs (later occurrence of the distractor word information) yielded longer-latency effects. Second, as was observed in the RT data, the profile of the incongruency effect amplitudes across the SOAs depended heavily on the within-run arrangement of the SOA trial types.
To quantitatively assess the influence of SOA arrangement on the response profiles of these components, we first considered the local peak latencies. Using the local peak latencies of the grand-averaged incongruency difference waveform as a starting point (listed as "Grand-Averaged Latency" in Table 2), the individual-subject local peak latencies occurring within \pm 150 msec of the grand-averaged peak were extracted (Figure $4 \mathrm{~A})$. rANOVAs on these values demonstrated a significant main effect of SOA $[F(4,36)=$ $\left.60.13, p=<.001, \eta_{p}{ }^{2}=0.87\right]$ on the latencies of the $\mathrm{N}_{\mathrm{INC}}$ and a nearly significant main effect of SOA on the LPC latencies $\left[F(4,36)=2.47, p=.06, \eta_{p}{ }^{2}=0.22\right]$, but no main effect of SOA Arrangement $\left(\mathrm{N}_{\mathrm{INC}}:[F(1,36)=1.84, p=.21\right.$, $\left.\eta_{p}{ }^{2}=0.17\right]$; LPC: $\left.\left[F(1,36)=1.01, p=.34, \eta_{p}{ }^{2}=0.10\right]\right)$ or a $\mathrm{SOA} \times \mathrm{SOA}$ Arrangement interaction $\left(\mathrm{N}_{\mathrm{INC}}:[F(4,36)=0.77\right.$,

Table 2. Grand-Averaged Peak $\mathrm{N}_{\mathrm{INC}}$ and LPC Amplitudes $(\mu \mathrm{V})$ and Latencies (msec) for the Random-SOA and Constant-SOA Tasks across the Five SOAs

\begin{tabular}{|c|c|c|c|c|c|c|c|c|c|c|}
\hline \multirow{3}{*}{$\begin{array}{l}\text { Grand-Averaged } \\
\text { Latency }\end{array}$} & \multicolumn{2}{|c|}{$-200 S O A$} & \multicolumn{2}{|c|}{$-100 S O A$} & \multicolumn{2}{|c|}{$O S O A$} & \multicolumn{2}{|c|}{+100 SOA } & \multicolumn{2}{|c|}{$+200 S O A$} \\
\hline & Random & Constant & Random & Constant & Random & Constant & Random & Constant & Random & Constant \\
\hline & $320 \mathrm{msec}$ & $286 \mathrm{msec}$ & $348 \mathrm{msec}$ & $362 \mathrm{msec}$ & $424 \mathrm{msec}$ & $446 \mathrm{msec}$ & $518 \mathrm{msec}$ & $544 \mathrm{msec}$ & 536 msec & $538 \mathrm{msec}$ \\
\hline \multirow[t]{2}{*}{$\mathrm{N}_{\text {INC }}$ amplitude $(\mu \mathrm{V})$} & -3.68 & -1.66 & -2.24 & -1.83 & -1.79 & -3.35 & -1.06 & -1.39 & -1.28 & -2.15 \\
\hline & \multicolumn{2}{|c|}{$p=.01 *$} & \multicolumn{2}{|c|}{$p=.21$} & \multicolumn{2}{|c|}{$p=.02 *$} & \multicolumn{2}{|c|}{$p=.26$} & \multicolumn{2}{|c|}{$p=.08$} \\
\hline \multirow[t]{3}{*}{$\mathrm{N}_{\mathrm{INC}}$ latency (msec) } & 325 & 320 & 368 & 363 & 393 & 432 & 523 & 544 & 589 & 607 \\
\hline & $p=$ & .40 & $p=$ & .36 & $p=$ & & $p=$ & .15 & $p=$ & .24 \\
\hline & $654 \mathrm{msec}$ & $512 \mathrm{msec}$ & $698 \mathrm{msec}$ & $610 \mathrm{msec}$ & $888 \mathrm{msec}$ & $926 \mathrm{msec}$ & $912 \mathrm{msec}$ & $932 \mathrm{msec}$ & 936 msec & $904 \mathrm{msec}$ \\
\hline \multirow[t]{2}{*}{ LPC amplitude $(\mu \mathrm{V})$} & 3.74 & 2.34 & 2.67 & 3.40 & 2.59 & 2.97 & 3.22 & 2.99 & 2.35 & 1.66 \\
\hline & \multicolumn{2}{|c|}{$p=.04^{*}$} & \multicolumn{2}{|c|}{$p=.44$} & \multicolumn{2}{|c|}{$p=.60$} & \multicolumn{2}{|c|}{$p=.69$} & \multicolumn{2}{|c|}{$p=.50$} \\
\hline \multirow[t]{2}{*}{ LPC latency (msec) } & 648 & 663 & 741 & 708 & 781 & 755 & 824 & 761 & 760 & 727 \\
\hline & \multicolumn{2}{|c|}{$p=.63$} & \multicolumn{2}{|c|}{$p=.29$} & \multicolumn{2}{|c|}{$p=.66$} & \multicolumn{2}{|c|}{$p=.16$} & \multicolumn{2}{|c|}{$p=.60$} \\
\hline
\end{tabular}

Significant paired $t$ test results are indicated with asterisks. 
$\left.p=.55, \eta_{p}{ }^{2}=0.08\right]$; LPC: $\left[F(4,36)=0.46, p=.77, \eta_{p}{ }^{2}=\right.$ $0.05])$, on the latency of either component. These main effects of SOA were in turn driven by a significant linear trend $[F(1,9)=104.77, p<.001]$ for the $\mathrm{N}_{\text {INC }}$ and a marginally significant linear trend $[F(1,9)=3.67, p=.089]$ for the LPC component. In agreement with the absence of main effects of SOA arrangement, paired $t$ tests confirmed that the peak latencies did not differ between the two SOA arrangement variants at any of the SOAs, for either the $\mathrm{N}_{\text {INC }}$ or LPC components. To further investigate the linear trends in these responses, post hoc paired comparisons were performed between the latencies at each SOA for each component collapsed over the two tasks. These analyses revealed that for the $\mathrm{N}_{\mathrm{INC}}$, each successive SOA evoked a longer latency response than the previous SOA (all $p<.01)$. In contrast, LPC latencies increased monotonically between the $-200,-100$, and 0 msec SOAs $(p<$ $.05)$ but were not statistically different for the 0 and +100 SOA $(p=.22)$ or between the +100 and +200 msec SOAs $(p=.18)$.

In contrast, as can be seen in Figure $4 \mathrm{~B}$, the amplitude patterns of the incongruency effects differed substantially between the two SOA Arrangement variants of the task, with the effect amplitudes being largest at the $-200 \mathrm{msec}$ SOA for the random arrangement and at $0 \mathrm{msec}$ (simultaneous) for the blocked one. ANOVAs performed on the $\mathrm{N}_{\text {INC }}$ peak amplitudes of these effects indeed confirmed both a main effect of SOA $\left[F(4,36)=5.26, p=.011, \eta_{p}{ }^{2}=\right.$ $0.36]$ and a significant SOA $\times$ SOA Arrangement interaction $\left[F(4,36)=5.21, p=.009, \eta_{p}^{2}=0.37\right]$. Subsequent paired $t$ test comparisons between the two task variants revealed significant differences for the $-200 \mathrm{msec}$ SOA condition $(p=$ $.01)$ and for the 0 msec SOA condition $(p=.02)$. Peak LPC amplitudes showed neither main effects, nor significant SOA $\times$ SOA Arrangement interactions, although planned paired $t$ tests indicated a significant reduction in the LPC amplitude of the -200 SOA condition for the constantSOA task.

\section{Sensory Biasing due to SOA Arrangement}

Having established that the arrangement of SOAs within a task-evoked different patterns of SOA-incongruency interaction, both behaviorally and for the $\mathrm{N}_{\text {INC }}$ ERP effect, we probed the data further to determine whether there were alterations in the stimulus processing that may have accompanied these conflict-dependent modulations. In particular, we analyzed the sensory-evoked activity to the task-irrelevant word stimulus in the -200 msec SOA condition, which provides an uninterrupted window of at least $200 \mathrm{msec}$ following the first stimulus component (S1) during which no other overlapping stimulus response is present. On the basis of previous reports of cortical biasing because of attentional selection (Hillyard \& Anllo-Vento, 1998; Anllo-Vento \& Hillyard, 1996), we probed the response amplitudes over fronto-central and lateral-occipital ROIs to test the hypothesis that the SOA arrangement might be accompanied by differential processing of the evoked response to the irrelevant distractor when it always comes predictably first versus when the SOAs are random across trials.

ERPs time-locked to the S1 stimulus in the $-200 \mathrm{msec}$ SOA condition (i.e., when the task-irrelevant distractor word came $200 \mathrm{msec}$ before the color bar) showed no difference between the congruent and incongruent trial types over the first $300 \mathrm{msec}$. This result was expected because

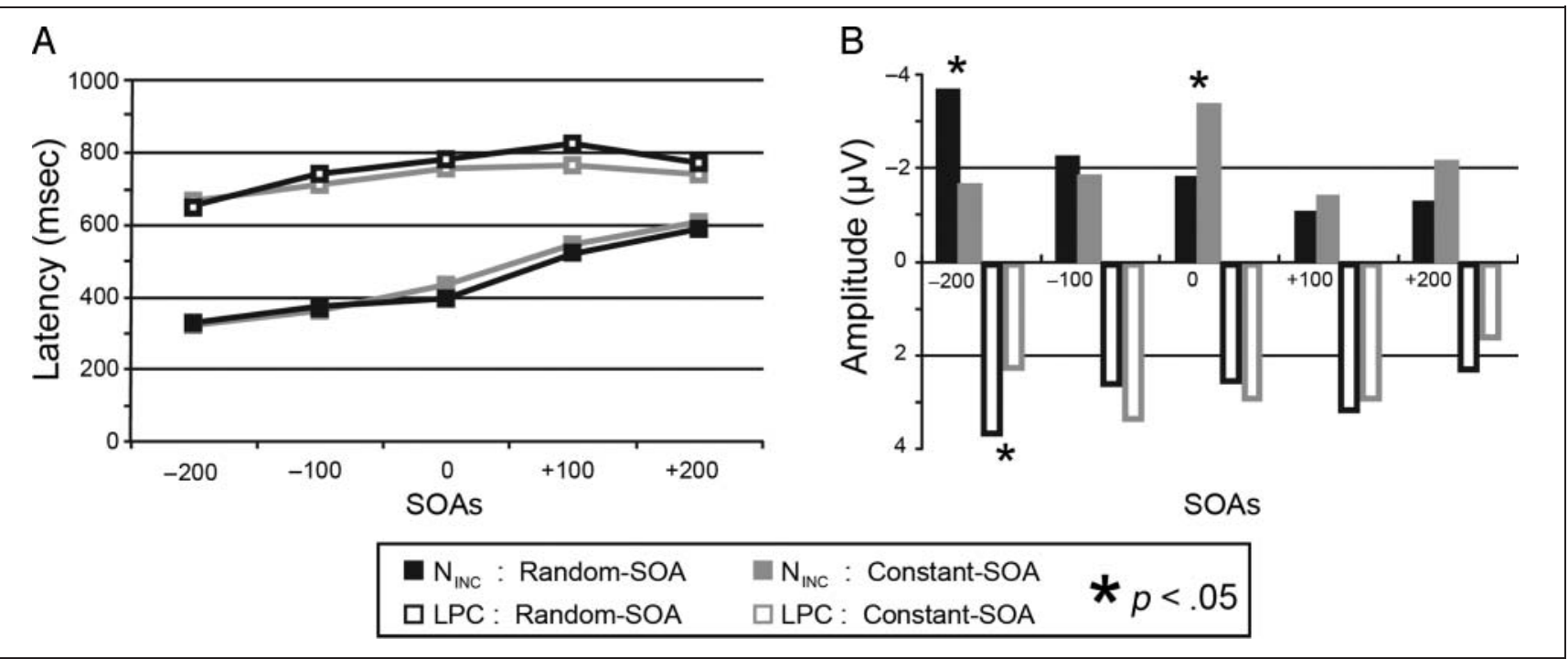

Figure 4. Quantitative summary of ERP measures. Peak latencies (A) and peak amplitudes (B) for the random-SOA and constant-SOA task variants across the five SOAs. Average $\mathrm{N}_{\text {INC }}$ (filled symbols) and LPC (open symbols) latencies did not differ for the two tasks at any SOA. In close agreement with the behavioral effects, however (see Figure 2), the incongruency-effect amplitudes produced differing SOA by SOA arrangement profiles. In particular, at the $-200 \mathrm{msec} \mathrm{SOA}$, the random-SOA arrangements produced greater activity for both the $\mathrm{N}_{\mathrm{INC}}$ and the LPC, whereas at the 0 msec SOA $\mathrm{N}_{\mathrm{INC}}$ activity was larger for the constant-SOA task. Significant paired $t$ test results are indicated with asterisks. 
A

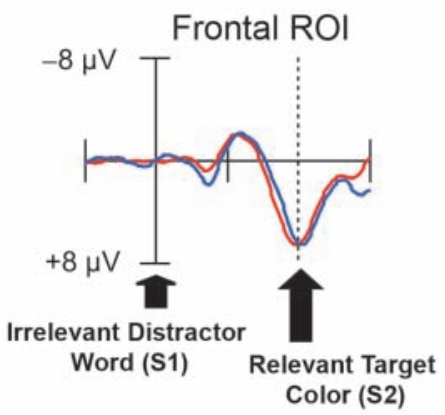

ERPs time-locked to S1

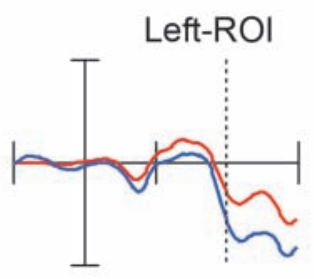

Random

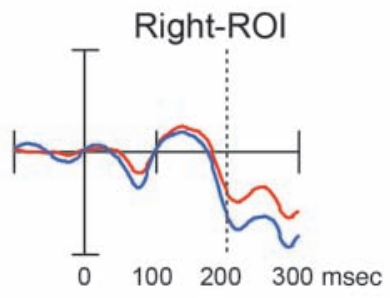

Constant
ROI locations

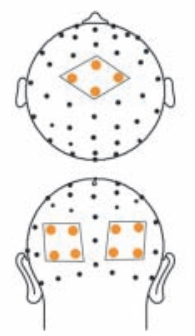

B ERP difference topography: random-SOA minus constant-SOA

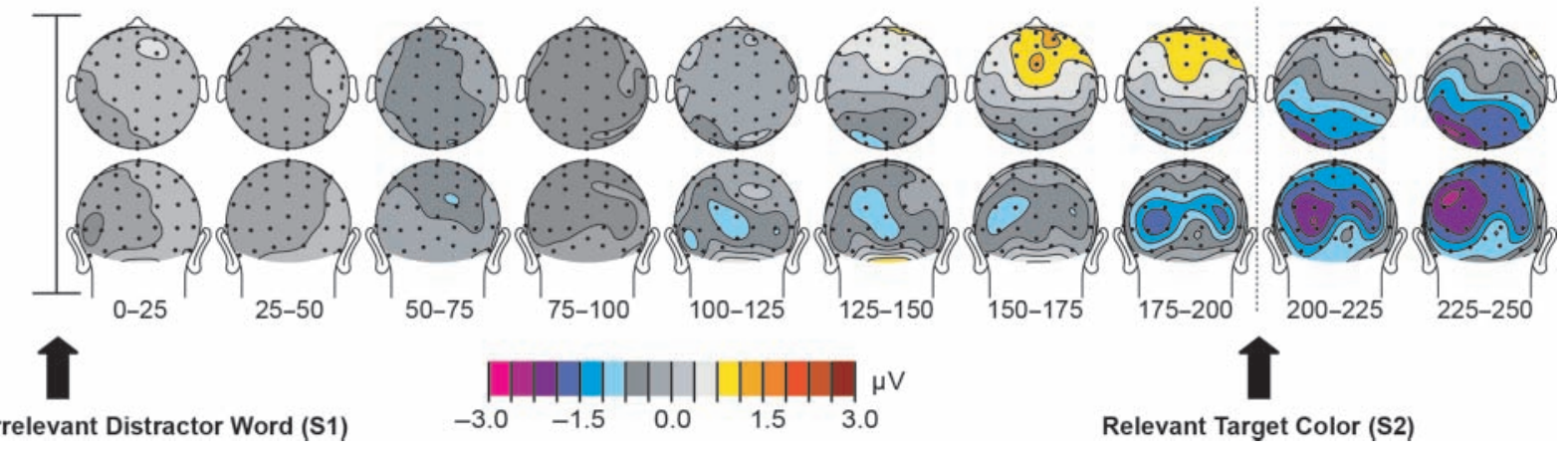

Figure 5. Distractor predictability modulates sensory stimulus processing. To visualize task differences due to the arrangement of SOAs, randomand constant-SOA waveforms, along with topographic distributions of the difference between these two conditions, are shown for the - 200 msec SOA (i.e., when the distractor word occurred $200 \mathrm{msec}$ before the target color bar to be named). (A) ERPs time-locked to the distractor word (S1) are shown for the random-SOA (red) and constant-SOA (blue) task variants. Each of these waveforms is collapsed over congruent and incongruent trial types as congruency has no meaning before the presentation of the S2 stimulus. (B) Topographic distribution of the random-SOA minus constant-SOA difference for the S1-elicited ERP in the $-200 \mathrm{msec}$ SOA condition. This subtraction produces a frontal-positive/occipital-negative difference that initiates before the S2 stimulus presentation, indicating modulations in visual processing of the distractor word stimulus because of the SOA arrangement of the task.

the influence of compatibility between the S1 and S2 stimulus components has no meaning before the occurrence and processing of the second stimulus (S2). Subsequent analyses of the time range before and around the presentation of S2 were therefore collapsed over the congruent and incongruent trial types and are shown visually in Figure 5.

ANOVAs performed over $25 \mathrm{msec}$ windows for the anterior and posterior ROIs (orange dots in Figure $5 \mathrm{~A}$ ) revealed a significant $(p=.028)$ difference over fronto-central electrodes that was more positive from 150 to $175 \mathrm{msec}$ post-S1 for random than constant trial types. This difference onset at around the same time as a bilateral posterior difference that was more negative for random than constant trial types, which was significant through the four $25 \mathrm{msec}$ windows beginning at $150 \mathrm{msec}(150-175 \mathrm{msec}, p=.039$; $17-$ $200 \mathrm{msec}, p=.007 ; 200-225 \mathrm{msec}, p=.004,225-250 \mathrm{msec}$, $p=.014)$. These posterior effects were significantly larger in the left than in the right ROI at $200-225 \operatorname{msec}(p=$ $.011)$ and $225-250 \mathrm{msec}(p=.014)$. At latencies beyond $\sim 250 \mathrm{msec}$, the cortical ERP to the S2 bar stimulus would necessarily begin and would overlap and distort the ERP activity evoked in response to the S1, and thus, activity in these longer latencies are not considered here.

\section{DISCUSSION}

Goal-oriented behavior requires flexible mechanisms that are able to select correct actions in the presence of many competing external stimuli, especially when some of those stimuli may be associated with incorrect responses. Strategic processes that govern these abilities vary as a function of the context under which choices are made and represent a critical adaptive mechanism by which behavior is optimized. In the present work, we used variants of the Stroop task in which temporal separations between the task-relevant color elements and the task-irrelevant word elements of each of the stimuli were varied, either randomly intermixed or held constant within an experimental run. By comparing behavioral and neural-activity differences that accompanied Stroop conflict under these arrangements, we were able to infer how the temporal predictability of stimuli in the environment may lead to strategic cognitive adjustments. 


\section{The Influence of Temporal Predictability on Stimulus Incongruency}

Behavioral results from SOA variants of the Stroop task are generally regarded as key, robust findings that must be accounted for in successful models of conflict processing in the Stroop and related tasks (Roelofs, 2003; MacLeod, 1991). It is generally appreciated from numerous SOA variants of the Stroop task that the irrelevant stimulus element is able to cause interference if it appears at any point before target processing is finished. A number of previous behavioral Stroop-SOA tasks have typically reported that incongruency effects are greatest when the SOA between the two dimensions is close to $0 \mathrm{msec}$, falling off for either positive or negative SOAs (Lu \& Proctor, 2001; Sugg \& McDonald, 1994; Glaser \& Dungelhoff, 1984; Glaser \& Glaser, 1982; Taylor, 1977; Dyer, 1971). In addition to this inverted u-shaped incongruency function, these studies have tended to show that the pre-exposure of irrelevant stimuli elicits somewhat greater RT slowing than comparable post-exposure of the distractor (e.g., $\sim 75 \mathrm{msec}$ for -200 SOA compared with $\sim 25$ msec for +200 as measured by Glaser \& Glaser, 1982), although with both less than simultaneous occurrence.

In our previous article (Appelbaum, Meyerhoff, et al., 2009), we recorded both behavioral and EEG measures of stimulus conflict processing in a Stroop-SOA task variant in which the task-irrelevant color words could appear at one of five SOAs relative to the task-relevant bar color occurrence: 100 or 200 msec before, 100 or 200 msec after, or simultaneously. In this design, however, the SOAs were randomly intermixed from trial-to-trial within each experimental run. This arrangement produced the greatest behavioral and electrophysiological effects when irrelevant stimulus information preceded the task-relevant target and reduced effects when the irrelevant information followed the relevant target. We interpreted this pattern of effects as reflecting two separate processes: (1) a "priming influence" that enhanced the magnitude of the conflictrelated incongruency effect when a task-relevant target was preceded by an irrelevant distractor and (2) a reduced "backward influence" of stimulus conflict when the irrelevant distractor information followed the task-relevant target. As this pattern of incongruency by SOA effects differed from the commonly reported inverted-U incongruency pattern for behavioral effects that had typically been reported with blocked SOA designs, we pursued in the present experiment to specifically test the influence of SOA arrangement on Stroop behavioral and neural incongruency effects.

Direct comparisons of the incongruency effects collected under conditions of constant- and random-SOA arrangements in this study indicate that the increased pre-exposure priming of the incongruency effects observed in our original experiment may indeed be due to the temporal uncertainty introduced by the randomSOA arrangements. Consistent with our previous results,
random-SOA arrangements produced RT and electrophysiological effects that were robustly larger (nearly twice) at the -200 msec SOA relative to the simultaneous presentation. Importantly, this effect was reversed for the constant-SOA arrangement (significantly larger for simultaneous than with 200 msec SOA). Moreover, this condition showed differential early-latency processing differences for the S1 stimulus relative to in the random-SOA arrangement. This combination of results suggests that with temporal predictability of potentially conflicting input, participants are better able to impose temporally selective filters that reduce the influence of the irrelevant stimulus dimension. In the absence of such temporal predictability, the processing of the irrelevant distractor would necessarily be relatively unconstrained and could thereby result in greater pretarget priming for the random-SOA condition. It is of importance to note that the random-SOA arrangement seems likely to have important ecological validity given that conflicting or distracting stimuli in the natural world frequently do not occur with temporal regularities, and therefore the distinction between stimulus conflict processing under randomized and predictable temporal arrangements provides an important new contribution to the Stroopconflict literature.

In the current constant-SOA task, incongruency effects were greatest at the $0 \mathrm{msec}$ SOA, in line with the behavioral results pattern reported by MacLeod (1991) and Roelofs $(2003)^{3}$ using this SOA configuration and with recent computational simulations of the Stroop-SOA effect (Yu \& Choe, 2006). A further observation of interest in this study is that according to paired comparisons, both the behavioral and ERP effect sizes were larger at the 0 msec SOA for the constant-SOA arrangements than for the randomSOA one. Because in either SOA arrangement, the simultaneous presentation of distractors and targets would not be expected to result in any differential amount of priming, it can be inferred that other mechanisms beyond a strict temporal filter may be contributing to the overall pattern of incongruency effects observed here. In fact, this result resembles findings reported by Mattler (2003), who observed larger effects of time uncertainty at short SOAs for spatially induced conflict resulting from Flanker incongruency. Given such observations, it may be the case that in the constant-SOA arrangement the synchronous presentation of the color and word stimuli may induce relatively more binding of the two elements, greater processing of the distractor, and therefore larger overall incongruency effects in relation to the random-SOA condition. Nonetheless, future research will be needed to assess such hypotheses.

The present results may also bear a close resemblance to the cued temporal orienting literature (Griffin, Miniussi, \& Nobre, 2001; Nobre, 2001; Miniussi, Wilding, Coull, \& Nobre, 1999; Coull \& Nobre, 1998). Although there have not been a great many of such studies, they have utilized interval manipulations in a variety of cue-to-target tasks to demonstrate that time interval expectation can guide the attentional selection of stimuli to improve behavior. It is 
worth noting, however, that in the present tasks participants were not explicitly informed about the temporal arrangement of the stimuli, as they have been in the cued temporal orienting studies. The contextual effects observed here must, therefore, be a quickly emergent property that is derived from the recent history of trials in the experimental runs, rather than any prespecified cue meaning. This notwithstanding, the present results indicate that the processing of stimulus conflict can be influenced by strategic attentional orienting in time.

\section{The Temporal Dynamics of Stroop Incongruency as Revealed by ERPs}

Measurement of scalp-recorded ERPs have provided an important means by which to explore the time course of brain processes underlying Stroop conflict (e.g., West et al., 2005; Markela-Lerenc et al., 2004; Atkinson, Drysdale, \& Fulham, 2003; Hesse, Moller, Arnold, \& Schack, 2003; West \& Alain, 1999; Rebai, Bernard, \& Lannou, 1997). As with the present findings, typical ERP studies of the Stroop task report that responses to incongruent stimuli, as compared with congruent stimuli, tend to elicit a negative voltage deflection that is centrally distributed over the head and peaks at around $450 \mathrm{msec}$ poststimulus (Bruchmann, Herper, Konrad, Pantev, \& Huster, 2010; BadzakovaTrajkov, Barnett, Waldie, \& Kirk, 2009; Larson et al., 2009; Hanslmayr et al., 2008; Lansbergen, van Hell, \& Kenemans, 2007; Perlstein et al., 2006; West et al., 2005; West, 2003; Van Veen \& Carter, 2002; Liotti et al., 2000; West \& Alain, 1999; Rebai et al., 1997). This component, often referred to as the $\mathrm{N} 450$, here termed the $\mathrm{N}_{\mathrm{INC}}$, is thought to index incongruency-related interactions that occur at a rather late point in the cortical processing hierarchy, following initial stimulus evaluation. In fact, several ERP studies have shown that Stroop incongruency has little effect on the amplitude or latency of the common P300 component, which is sensitive to the probability and task relevance of an eliciting stimulus (Rosenfeld \& Skogsberg, 2006; Ilan \& Polich, 1999; Duncan-Johnson \& Kopell, 1981). Similarly, modulations akin to the P300 do not appear to be present in the current tasks.

Studies investigating the neural sources of the $\mathrm{N}_{\mathrm{INC}}$ / N450 effect have typically modeled this component as arising from generators in the dorsal ACC (BadzakovaTrajkov et al., 2009; Hanslmayr et al., 2008; Markela-Lerenc et al., 2004; West, Bowry, \& McConville, 2004; West, 2003; Liotti et al., 2000). However, more recent source localization efforts have suggested additional contributions from generators in the lateral prefrontal and more superior medial frontal regions, as well as possibly the motor cortices bilaterally (Bruchmann et al., 2010). As in our previous study (Appelbaum, Meyerhoff, et al., 2009), the response distribution of the present incongruency negativity produced a broad central-parietal deflection. This somewhat posterior distribution is largely consistent with that reported by Liotti et al. (2000) and West and Alain (1999) for a manual response Stroop task and is potentially consistent with a source in the more posterior regions of ACC (Liotti et al., 2000; West \& Alain, 1999; Rebai et al., 1997).

The present incongruency subtraction also produced a more sustained, parietal positive/lateral frontal negative wave occurring between 500 and 900 msec poststimulus that is largely consistent with similar components reported at later latencies in other Stroop conflict tasks (Bailey, West, \& Anderson, 2009; Larson et al., 2009; Perlstein et al., 2006; West et al., 2005; West, 2003; Liotti et al., 2000; West \& Alain, 2000). This tonic, conflict-sensitive potential, typically termed either the conflict sustained potential (conflict-SP) or the late positive component (LPC) by different researchers, is more positive for incongruent relative to congruent trials over parietal electrode sites and tends to be somewhat larger over the left than the right hemisphere. As the amplitude of the LPC is positively correlated with both accuracy and RT with incongruent stimuli, it has been suggested that this component may be associated with response selection on the current trial (West et al., 2005). Alternately, based on the timing and distribution, others have suggested that the LPC may be related to the processing of semantic meaning of the Stroop stimulus words (Liotti et al., 2000).

\section{Microscopic and Macroscopic Cognitive Control Influences on the ERP}

In recent years, researchers have begun to study how strategic properties, such as the degree of impulsivity or cautiousness influence the flexible regulation of behavior (Egner, 2007; Botvinick, Braver, Barch, Carter, \& Cohen, 2001) and whether such regulation is implemented at the local or global level (Blais \& Bunge, 2010). In general, the application of strategic processes has been subdivided into two broad classes: microadjustments that act from trial to trial to alter performance based on the recent history of stimuli and/or the commission of incidental errors and macroadjustments that involve long-term modifications in response to the context under which different types of stimulus events occur (Ridderinkhof, 2002).

ERPs possess millisecond temporal resolution and are therefore particularly well suited for investigating the dynamic microadjustments that are made in response to specific factors that change rapidly over time. Recent ERP research has begun to focus on how the sequence of different trial types manifests in differential effects on conflict-induced ERPs components such as the $\mathrm{N}_{\text {INC }}$ (N450) and LPC (conflict-SP). One such type of firstorder sequence effects is the so-called conflict adaptation effect in which trials containing a relatively high (incongruent) versus low (congruent) amount of conflict induce corresponding reductions or enhancements in the influence of the irrelevant stimulus dimension during the subsequent trial. In one recent experiment, Larson and colleagues (2009) investigated the influence of conflict adaptation on the $\mathrm{N}_{\text {INC }}$ and LPC components. They 
reported that, although the LPC monotonically differentiated current trial congruency on the basis of previous-trial context, no such conflict adaptation effects were observed in the amplitude of the $\mathrm{N}_{\mathrm{INC}}$ component.

Macroscale conflict-related adjustments are those that occur in response to factors that are likely to remain constant for some time. One experimental manipulation that has been extensively used to study the behavioral ramifications and neural mechanisms that correspond to macro adjustments has been to alter the level of conflict potency by varying the relative proportion of congruent versus incongruent trials presented in an experimental run. Such "trial-type frequency" manipulations have demonstrated that increasing the probability of incongruent trials reduces not only the magnitude of the behavioral incongruency effects (Larson et al., 2009; Schmidt \& Besner, 2008; Crump, Gong, \& Milliken, 2006; Rosenfeld \& Skogsberg, 2006; Botvinick et al., 2001; Tzelgov et al., 1992; Glaser \& Dungelhoff, 1984; Glaser \& Glaser, 1982; Logan \& Zbrodoff, 1979; Taylor, 1977) but also the amplitude of ERP responses to these stimuli (West \& Alain, 2000), suggesting that macroscopic control can be experimentally manipulated and measured in the brain.

Results from the present experiment demonstrate a pattern of macroscale adjustments that result from trialtype context differences that are in place over a relatively long time frame (i.e., blocks, not trial to trial). We observed that the conflict-related $\mathrm{N}_{\text {INC }}$ component produced a pattern of amplitude effects that closely matched the incongruencyrelated RT effects over the two SOA arrangements. For both arrangements, greater behavioral RT effects corresponded to larger $\mathrm{N}_{\mathrm{INC}}$ amplitudes, and therefore, it can be concluded that the arrangement of SOA trials serves as an effective means by which to adjust the level of conflict potency on a macroscopic scale.

\section{Evidence That Temporal Predictability Modulates Stimulus Conflict Processing}

Previous studies have suggested that conflict resolution can be accompanied by neural strategies that act to bias stimulus processing in sensory pathways to facilitate behavioral performance (Egner, Delano, \& Hirsch, 2007; Cohen et al., 1990). Direct evidence for such conflict-related stimulus-biasing indicates that the cortical representations of task-relevant stimulus features are amplified relative to task-irrelevant ones during sequential-trial conflict adaptation (Egner \& Hirsch, 2005). ERP studies, in particular, have reported that the context under which stimulus-response conflict occurs modulates stimulus processing as early as the P1 (Scerif et al., 2006) and N2 (Folstein \& Van Petten, 2008) components. One possibility that has been widely postulated is that these modulations are achieved through sensory amplification or "gain control" effects that would be reflected in ERPs by larger P1 and N1 sensory-evoked responses being elicited by attended input relative to ignored input (Hillyard, Vogel, \& Luck, 1998; Posner \&
Driver, 1992). Alternately, such contextually driven adjustments act to modulate feature-specific mechanisms, which would be revealed by later-latency ERP effects such as the selection negativity and selection positivity (SN/SP; Hillyard \& Anllo-Vento, 1998; Anllo-Vento \& Hillyard, 1996).

To evaluate if context-driven modulations in stimulusevoked processing were present for the current tasks, we carried out analyses of the sensory-evoked component to the irrelevant distractor stimulus component (S1) for the -200 msec SOA under the two SOA arrangements. In this analysis, we observed clear differences in the ERP to the S1 stimulus as a function of the temporal predictability because of the SOA arrangement. This difference initiated at $\sim 150$ msec post-S1 as a bilateral occipital deflection that was more negative for the random-SOA than for the constant-SOA arrangements, concurrently with a frontocentral positive deflection difference. The posterior negative difference was more pronounced in the left than right hemisphere and increased in amplitude till well after the presentation of the S2 stimulus.

Overall, these patterns of ERP modulations would suggest that the task differences captured here reflect operations more akin to the selection of relevant stimulus features associated with feature selection ERP effects, rather than early $\mathrm{P} 1 / \mathrm{N} 1$ modulations that accompany sensory amplification or "gain control" that tends to occur with spatial attention. In particular, both the latencies and distributions of the present effects bear a close resemblance to the SN ERP effect that has been linked the selection of relevant features including color (Hillyard \& Munte, 1984; Harter, Aine, \& Schroeder, 1982) and other nonspatial features (Kenemans, Kok, \& Smulders, 1993). This effect has consisted of a bilateral, posterior negativity (SN) that typically occurs between 150 and $300 \mathrm{msec}$, which is sometimes accompanied by and a frontal positivity (sometimes called "SP"). The onset of the SN/SP waveform provides a high-resolution measure of the time at which a particular feature or feature conjunction is discriminated and selectively processed according to its task relevance (Hillyard \& Anllo-Vento, 1998). Accordingly, it may serve as a plausible mechanism by which stimulus conflict from a task-irrelevant feature can be mitigated in the current Stroop-SOA tasks.

The occipital negative effects derived from this task subtraction also demonstrate a degree of left lateralization. One possible explanation for this lateralization comes from the N170 ERP literature. The N170 component is a leftlateralized ERP wave that has been reported as showing prelexical sensitivity to orthographic versus nonorthographic strings (Appelbaum, Liotti, Perez, Fox, \& Woldorff, 2009; Ruz \& Nobre, 2008; Bentin, Mouchetant-Rostaing, Giard, Echallier, \& Pernier, 1999). As the sensory response considered here is that of the task-irrelevant word component, it is reasonable that the task modulations reported here may also contain some degree of left lateralization. An alternate account of this lateralization may come from the temporal framework literature. In the account of their temporal orienting effects Coull and Nobre (1998) 
reported a pronounced "left-sided bias in activations during temporal orienting [that] was reminiscent of the laterality in tasks involving fine temporal discriminations." It may therefore be the case that the present task differences are also tapping into mechanisms that are invoked during the temporal discrimination of rapidly occurring stimulus events (Platel et al., 1997; Fiez, Raichle, Petersen, Tallal, \& Katz, 1995).

\section{Comparison with Recent Study of Temporal Predictability Effects by Roelofs (2010)}

Although SOA manipulations have been applied to Stroop tasks since as early as 1971 (Dyer, 1971), the first direct empirical test of the temporal predictability hypothesis applied to the Stroop task has only recently been attempted. In this study, Roelofs (2010) used constantand random-SOA arrangements in different runs to test how temporal predictability influenced incongruency effects in verbal naming variants of the Stroop-SOA task. In direct contrast to the present results, Roelofs reported seeing no evidence of strategic orienting due to the temporal arrangement of the SOAs, reporting that behavioral interference was greatest at the 0 msec SOA for both intermixed and blocked SOA conditions.

As discussed by MacLeod (1991) in his extensive review of the Stroop literature, there are a considerable number of factors that can influence the type and degree of congruency-related interactions elicited in the Stroop task. One such factor is the behavioral response modality used. Previous literature has reported behavioral performance differences depending on response mode (Barch et al., 2001; Weekes \& Zaidel, 1996), such that manual responses elicit generally faster overall RTs than vocal responses. Specifically as it relates to Stroop-SOA tasks, it has recently been demonstrated that changes in response modality can alter the pattern of incongruency effects in a Stroop-SOA task. As reported by Coderre et al. (2010), the peak of Stroop interference experiences a negative shift in a manual task such that it occurs at the $-200 \mathrm{msec}$ SOA rather than the $0 \mathrm{msec}$ SOA as observed for verbal responses. Accordingly, this response mode difference would be related to the earlier shift in incongruency effects in the present findings, relative to those of Roelofs. Thus, it is possible that the different response modes and the degree to which they are susceptible to responsetranslation effects may have at least partially contributed to differences reported between these two studies (e.g., see Sugg \& McDonald, 1994), an open possibility for future studies to disentangle.

\section{Conclusions}

In this study, we investigated the behavioral and brain adjustments that accompany stimulus conflict in the colornaming Stroop task when the relative timing of the conflicting stimulus elements were predictable versus when they were not. The results demonstrated that the pattern of behavioral and neural incongruency effects vary as a function of the temporal predictability, producing the greatest incongruency effects when the conflicting irrelevant stimulus is presented earlier than the target for unpredictable arrangements, but with simultaneous onset for the temporally predictable ones. Moreover, additional analysis of the sensory responses to the irrelevant distractors when they occurred before the target revealed a marked modulation of the early-latency stimulus processing between the two SOA arrangements, providing important evidence for a possible mechanism contributing to the differential incongruency effects. Thus, the current results indicate that, at least under some circumstances, participants are able to rapidly deduce temporally predictable contingencies between regularly occurring stimulus elements and invoke contextually driven cognitive control mechanisms to modulate interference effects that can be induced when these elements conflict.

\section{Acknowledgments}

This work was supported by grants from the National Institutes of Health (grants R01-MH60415 and R01-NS051048 to M. G. W.).

Reprint requests should be sent to L. Gregory Appelbaum, Center for Cognitive Neuroscience, Duke University, B203 LSRC, Box 90999, Durham, NC 27708, or via e-mail: greg@duke.edu.

\section{Notes}

1. The negative-polarity ERP wave associated with incongruency ( $\mathrm{N}_{\mathrm{INC}}$ ). This component is analogous to the previously reported N450 component observed in many 0-msec SOA versions of the Stroop task, but because the latency of this component varies with $\mathrm{SOA}$ in the present design, we will use the label $\mathrm{N}_{\mathrm{INC}}$.

2. This component has also been termed the conflict SP, representing the "conflict slow potential" (Larson et al., 2009) or "conflict sustained potential" (West et al., 2005; West, 2003). 3. These correspond to Points 4 and 11 in the respective text's "Critical Factors for Stroop Interference" tables.

\section{REFERENCES}

Anllo-Vento, L., \& Hillyard, S. A. (1996). Selective attention to the color and direction of moving stimuli: Electrophysiological correlates of hierarchical feature selection. Perception $\&$ Psychophysics, 58, 191-206.

Appelbaum, L. G., Liotti, M., Perez, R., Fox, S. P., \& Woldorff, M. G. (2009). The temporal dynamics of implicit processing of non-letter, letter, and word-forms in the human visual cortex. Frontiers in Human Neuroscience, 3, 56.

Appelbaum, L. G., Meyerhoff, K. L., \& Woldorff, M. G. (2009). Priming and backward influences in the human brain: Processing interactions during the stroop interference effect. Cerebral Cortex, 19, 2508-2521.

Atkinson, C. M., Drysdale, K. A., \& Fulham, W. R. (2003). Event-related potentials to Stroop and reverse Stroop stimuli. International Journal of Psychophysiology, 47, 1-21.

Badzakova-Trajkov, G., Barnett, K. J., Waldie, K. E., \& Kirk, I. J. (2009). An ERP investigation of the Stroop task: The role of the cingulate in attentional allocation and conflict resolution. Brain Research, 1253, 139-148. 
Bailey, K., West, R., \& Anderson, C. A. (2009). A negative association between video game experience and proactive cognitive control. Psychophysiology, 47, 34-42.

Barch, D. M., Braver, T. S., Akbudak, E., Conturo, T., Ollinger, J., \& Snyder, A. (2001). Anterior cingulate cortex and response conflict: Effects of response modality and processing domain. Cerebral Cortex, 11, 837-848.

Bentin, S., Mouchetant-Rostaing, Y., Giard, M. H., Echallier, J. F., \& Pernier, J. (1999). ERP manifestations of processing printed words at different psycholinguistic levels: Time course and scalp distribution. Journal of Cognitive Neuroscience, 11, 235-260.

Blais, C., \& Bunge, S. (2010). Behavioral and neural evidence for item-specific performance monitoring. Journal of Cognitive Neuroscience, 22, 2758-2767.

Botvinick, M. M., Braver, T. S., Barch, D. M., Carter, C. S., \& Cohen, J. D. (2001). Conflict monitoring and cognitive control. Psychological Review, 108, 624-652.

Broadbent, D. E. (1970). Stimulus set and response set: Two kinds of selective attention. In D. I. Mostofsky (Ed.), Attention: Contemporary theory and analysis (pp. 51-60). New York: Appleton-Century-Crofts.

Bruchmann, M., Herper, K., Konrad, C., Pantev, C., \& Huster, R. J. (2010). Individualized EEG source reconstruction of Stroop interference with masked color words. Neuroimage, 49, 1800-1809.

Coderre, E., van Heuven, W., \& Conklin, K. (2010). Lexical access and executive control in monolinguals and bilinguals. Paper presented at the Architectures and Mechanisms for Language Processing, York, UK.

Cohen, J. D., Dunbar, K., \& McClelland, J. L. (1990). On the control of automatic processes: A parallel distributed processing account of the Stroop effect. Psychological Review, 97, 332-361.

Coull, J. T., \& Nobre, A. C. (1998). Where and when to pay attention: The neural systems for directing attention to spatial locations and to time intervals as revealed by both PET and fMRI. Journal of Neuroscience, 18, 7426-7435.

Crump, M. J., Gong, Z., \& Milliken, B. (2006). The context-specific proportion congruent Stroop effect: Location as a contextual cue. Psychonomic Bulletin E Review, 13, 316-321.

Duncan-Johnson, C. C., \& Kopell, B. S. (1981). The Stroop effect: Brain potentials localize the source of interference. Science, 214, 938-940.

Dyer, F. N. (1971). The effect of word meaning response: Stroop interference for different preexposures of the word. Psychonomic Science, 25, 229-231.

Egner, T. (2007). Congruency sequence effects and cognitive control. Cognitive, Affective \& Behavioral Neuroscience, 7 , $380-390$.

Egner, T. (2008). Multiple conflict-driven control mechanisms in the human brain. Trends in Cognitive Sciences, 12, 374-380.

Egner, T., Delano, M., \& Hirsch, J. (2007). Separate conflictspecific cognitive control mechanisms in the human brain. Neuroimage, 35, 940-948.

Egner, T., \& Hirsch, J. (2005). Cognitive control mechanisms resolve conflict through cortical amplification of task-relevant information. Nature Neuroscience, 8, 1784-1790.

Eriksen, B. A., \& Eriksen, C. W. (1974). Effects of noise letters upon the identification of a target letter in a nonsearch task. Perception \& Psychophysics, 16, 143-149.

Fiez, J. A., Raichle, M. E., Petersen, P. E., Tallal, P., \& Katz, W. F. (1995). PET studies of auditory and phonological processing effects of stimulus characteristics and task demands. Journal of Cognitive Neuroscience, 7, 357-375.

Flowers, J. H. (1990). Priming effects in perceptual classification. Perception \& Psychophysics, 47, 135-148.

Folstein, J. R., \& Van Petten, C. (2008). Influence of cognitive control and mismatch on the N2 component of the ERP: A review. Psychophysiology, 45, 152-170.

Glaser, M. O., \& Glaser, W. R. (1982). Time course analysis of the Stroop phenomenon. Journal of Experimental Psychology: Human Perception and Performance, 8, 875-894.

Glaser, W. R., \& Dungelhoff, F. J. (1984). The time course of picture-word interference. Journal of Experimental Psychology: Human Perception and Performance, 10, 640-654.

Glaser, W. R., \& Glaser, M. O. (1989). Context effects in strooplike word and picture processing. Journal of Experimental Psychology: General, 118, 13-42.

Griffin, I. C., Miniussi, C., \& Nobre, A. C. (2001). Orienting attention in time. Frontiers in Bioscience, 6, D660-D671.

Hanslmayr, S., Pastotter, B., Bauml, K. H., Gruber, S., Wimber, M., \& Klimesch, W. (2008). The electrophysiological dynamics of interference during the Stroop task. Journal of Cognitive Neuroscience, 20, 215-225.

Harter, M. R., Aine, C., \& Schroeder, C. (1982). Hemispheric differences in the neural processing of stimulus location and type: Effects of selective attention on visual evoked potentials. Neuropsychologia, 20, 421-438.

Hesse, W., Moller, E., Arnold, M., \& Schack, B. (2003). The use of time-variant EEG Granger causality for inspecting directed interdependencies of neural assemblies. Journal of Neuroscience Methods, 124, 27-44.

Hillyard, S. A., \& Anllo-Vento, L. (1998). Event-related brain potentials in the study of visual selective attention. Proceedings of the National Academy of Sciences, U.S.A. 95, 781-787.

Hillyard, S. A., \& Munte, T. F. (1984). Selective attention to color and location: An analysis with event-related brain potentials. Perception \& Psychophysics, 36, 185-198.

Hillyard, S. A., Vogel, E. K., \& Luck, S. J. (1998). Sensory gain control (amplification) as a mechanism of selective attention: Electrophysiological and neuroimaging evidence. Philosophical Transactions of the Royal Society of London, Series B, Biological Sciences, 353, 1257-1270.

Ilan, A. B., \& Polich, J. (1999). P300 and response time from a manual Stroop task. Clinical Neurophysiology, 110, 367-373.

Kenemans, J. L., Kok, A., \& Smulders, F. T. (1993). Event-related potentials to conjunctions of spatial frequency and orientation as a function of stimulus parameters and response requirements. Electroencephalography and Clinical Neurophysiology, 88, 51-63.

Lansbergen, M. M., van Hell, E., \& Kenemans, J. L. (2007). Impulsivity and conflict in the Stroop task: An ERP study. Journal of Psychophysiology, 21, 33059.

Larson, M. J., Kaufman, D. A., \& Perlstein, W. M. (2009). Neural time course of conflict adaptation effects on the Stroop task. Neuropsychologia, 47, 663-670.

Liotti, M., Woldorff, M. G., Perez, R., \& Mayberg, H. S. (2000). An ERP study of the temporal course of the Stroop color-word interference effect. Neuropsychologia, 38, 701-711.

Logan, G. D., \& Zbrodoff, N. J. (1979). When it helps to be misled: Facilitative effects of increasing of increasing the frequency of conflicting stimuli in a Stroop task. Memory and Cognition, 7, 166-174.

Long, G. M., \& Lyman, B. J. (1987). Foveal and parafoveal processing of asynchronous Stroop stimuli. British Journal of Psychology, 78, 151-162.

Lu, C. H., \& Proctor, R. W. (2001). Influence of irrelevant information on human performance: Effects of S-R association strength and relative timing. Quarterly Journal of Experimental Psychology A, 54, 95-136.

MacLeod, C. M. (1991). Half a century of research on the Stroop effect: An integrative review. Psychological Bulletin, 109, 163-203.

MacLeod, C. M., \& MacDonald, P. A. (2000). Interdimensional interference in the Stroop effect: Uncovering the cognitive 
and neural anatomy of attention. Trends in Cognitive Sciences, 4, 383-391.

Markela-Lerenc, J., Ille, N., Kaiser, S., Fiedler, P., Mundt, C., \& Weisbrod, M. (2004). Prefrontal-cingulate activation during executive control: Which comes first? Brain Research, Cognitive Brain Research, 18, 278-287.

Mattler, U. (2003). Delayed flanker effects on lateralized readiness potentials. [Clinical Trial Research Support, Non-U.S. Gov't]. Experimental Brain Research. Experimentelle Hirnforschung. Experimentation Cerebrale, 151, 272-288.

Miller, J. (1991). The flanker compatibility effect as a function of visual angle, attentional focus, visual transients, and perceptual load: A search for boundary conditions. Perception \& Psychophysics, 49, 270-288.

Miniussi, C., Wilding, E. L., Coull, J. T., \& Nobre, A. C. (1999) Orienting attention in time. Modulation of brain potentials. Brain, 122, 1507-1518.

Nobre, A. C. (2001). Orienting attention to instants in time. Neuropsychologia, 39, 1317-1328.

Perlstein, W. M., Larson, M. J., Dotson, V. M., \& Kelly, K. G. (2006). Temporal dissociation of components of cognitive control dysfunction in severe TBI: ERPs and the cued-Stroop task. Neuropsychologia, 44, 260-274.

Phaf, R. H., Van der Heijden, A. H., \& Hudson, P. T. (1990). SLAM: A connectionist model for attention in visual selection tasks. Cognitive Psychology, 22, 273-341.

Platel, H., Price, C., Baron, J. C., Wise, R., Lambert, J., Frackowiak, R. S., et al. (1997). The structural components of music perception. A functional anatomical study. Brain, 120, 229-243.

Posner, M. I., \& Driver, J. (1992). The neurobiology of selective attention. Current Opinion in Neurobiology, 2, 165-169.

Rayner, K., \& Springer, C. J. (1986). Graphemic and semantic similarity effects in the picture-word interference task. British Journal of Psychology, 77, 207-222.

Rebai, M., Bernard, C., \& Lannou, J. (1997). The Stroop's test evokes a negative brain potential, the N400. International Journal of Neuroscience, 91, 85-94.

Reynolds, M., Kwan, D., \& Smilek, D. (2010). To group or not to group: An ecological consideration of the stroop effect. Experimental Psychology, 57, 275-291.

Ridderinkhof, K. R. (2002). Micro- and macro-adjustments of task set: Activation and suppression in conflict tasks. Psychological Research, 66, 312-323.

Roberts, K. L., \& Hall, D. A. (2008). Examining a supramodal network for conflict processing: A systematic review and novel functional magnetic resonance imaging data for related visual and auditory stroop tasks. Journal of Cognitive Neuroscience, 20, 1063-1078.

Roelofs, A. (2003). Goal-referenced selection of verbal action: Modeling attentional control in the Stroop task. Psychological Review, 110, 88-125.

Roelofs, A. (2005). The visual-auditory color-word stroop asymmetry and its time course. Memory \& Cognition, 33, $1325-1336$.

Roelofs, A. (2006). Context effects of pictures and words in naming objects, reading words, and generating simple phrases. Quarterly Journal of Experimental Psychology (Colchester), 59, 1764-1784.

Roelofs, A. (2010). Attention, temporal predictability, and the time course of context effects in naming performance. Acta Psychologica (Amst), 133, 146-153.

Rosenfeld, J. P., \& Skogsberg, K. R. (2006). P300-based Stroop study with low probability and target Stroop oddballs: The evidence still favors the response selection hypothesis International Journal of Psychophysiology, 60, 240-250.

Ruz, M., \& Nobre, A. C. (2008). Attention modulates initial stages of visual word processing. Journal of Cognitive Neuroscience, 20, 1727-1736.
Scerif, G., Worden, M. S., Davidson, M., Seiger, L., \& Casey, B. J. (2006). Context modulates early stimulus processing when resolving stimulus-response conflict. Journal of Cognitive Neuroscience, 18, 781-792.

Schmidt, J. R., \& Besner, D. (2008). The Stroop effect: Why proportion congruent has nothing to do with congruency and everything to do with contingency. Journal of Experimental Psychology: Learning, Memory, and Cognition, 34, 514-523.

Simon, J. R. (1990). The effects of an irrelevant directional cue on human information processing. In R. W. Proctor \& T. G. Reeve (Eds.), Stimulus-response compatibility (pp. 31-86). Amsterdam: Elsevier.

Stafford, T., \& Gurney, K. N. (2007). Biologically constrained action selection improves cognitive control in a model of the Stroop task. Philosophical Transactions of the Royal Society of London, Series B, Biological Sciences, 362, 1671-1684.

Starreveld, P. A., \& La Heij, W. (1996). Time-course analysis of semantic and orthographic context effects in picture naming. Journal of Experimental Psychology, 22, 896-918.

Stroop, J. R. (1935). Studies of interference in serial verbal reactions. Journal of Experimental Psychology, 18, 643-662.

Sugg, M. J., \& McDonald, J. E. (1994). Time course of inhibition in color-response and word-response versions of the Stroop task. Journal of Experimental Psychology: Human Perception and Performance, 20, 647-675.

Taylor, D. A. (1977). Time course of context effects. Journal of Experimental Psychology: General, 4, 404-426.

Tzelgov, J., Henik, A., \& Berger, J. (1992). Controlling Stroop effects by manipulating expectations for color words. Memory \& Cognition, 20, 727-735.

Van Veen, V., \& Carter, C. S. (2002). The timing of actionmonitoring processes in the anterior cingulate cortex. Journal of Cognitive Neuroscience, 14, 593-602.

Weekes, N. Y., \& Zaidel, E. (1996). The effects of procedural variations on lateralized Stroop effects. Brain and Cognition, 31, 308-330.

West, R. (2003). Neural correlates of cognitive control and conflict detection in the Stroop and digit-location tasks. Neuropsychologia, 41, 1122-1135.

West, R., \& Alain, C. (1999). Event-related neural activity associated with the Stroop task. Brain Research, Cognitive Brain Research, 8, 157-164.

West, R., \& Alain, C. (2000). Effects of task context and fluctuations of attention on neural activity supporting performance of the stroop task. Brain Research, 873, 102-111.

West, R., Bowry, R., \& McConville, C. (2004). Sensitivity of medial frontal cortex to response and nonresponse conflict. Psychophysiology, 41, 739-748.

West, R., Jakubek, K., Wymbs, N., Perry, M., \& Moore, K. (2005). Neural correlates of conflict processing. Experimental Brain Research, 167, 38-48.

Woldorff, M. G. (1993). Distortion of ERP averages due to overlap from temporally adjacent ERPs: Analysis and correction. Psychophysiology, 30, 98-119.

Woldorff, M. G., Liotti, M., Seabolt, M., Busse, L., Lancaster, J. L., \& Fox, P. T. (2002). The temporal dynamics of the effects in occipital cortex of visual-spatial selective attention. Brain Research, Cognitive Brain Research, 15, 1-15.

Yu, Y., \& Choe, Y. (2006). Selective attention in time: An extended model of stimulus onset asynchrony (SOA) in Stroop effect. Paper presented at the Proceedings of the Fifth International Conference on Development and Learning, Indiana University, Bloomington, IN.

Zhang, H. H., Zhang, J., \& Kornblum, S. (1999). A parallel distributed processing model of stimulus-stimulus and stimulus-response compatibility. Cognitive Psychology, 38, $386-432$ 